\title{
First records of Dermacentor albipictus larvae collected by flagging in Yukon, Canada
}

\author{
Emily S. Chenery ${ }^{1 *} \mathbb{D}$, N. Jane Harms ${ }^{2} \mathbb{D}$, Nicholas E. Mandrak ${ }^{3}$ and Péter K. Molnár ${ }^{3}$
}

\begin{abstract}
Background: The winter tick (Dermacentor albipictus) has garnered significant attention throughout North America for its impact on wildlife health, and especially for moose (Alces alces), where high tick burdens may result in host hair loss, anemia, and can prove fatal. The environmental transmission of D. albipictus larvae to a host is a critical event that has direct impact on infestation success, yet in-field observations of this life stage are lacking. In Yukon, Canada, D. albipictus had previously been found on hosts, but its larval life stage had not been detected in the field, despite previous sampling attempts.

Methods: We sampled for D. albipictus larvae using traditional flagging methods in Ibex Valley and Braeburn, Yukon. Sites were sampled repeatedly for D. albipictus larvae by flagging from late August to end of October in 2018 and late August to end of November 2019.

Results: Larvae of D. albipictus were collected throughout Ibex Valley, at approximate densities ranging from 0.04 to 4236 larvae/100 $\mathrm{m}^{2}$. Larvae were present primarily on grassy vegetation on south-facing slopes in the Ibex Valley region and in Braeburn. Highest average larval numbers suggest peak questing activity was towards the end of September and beginning of October, as elsewhere in North America.

Conclusions: To the best of our knowledge, we report the first successful collection of the off-host, larval life stage of D. albipictus by flagging, north of $60^{\circ}$ latitude in Yukon, Canada. These new observations provide critical information on the spatial distribution of the host-seeking life stage of D. albipictus and confirm that this species is completing its whole life cycle in southern Yukon. Understanding the environmental conditions where larvae spend their vulnerable period off-host in this northern location can inform both management strategies and projections of future range expansion which may occur with a changing climate.
\end{abstract}

Keywords: Dermacentor albipictus, Flagging method, Larval tick, Winter tick, Yukon, Canada

\section{Background}

Understanding the off-host dynamics of tick life-cycles has profound implications for designing successful surveillance programmes [1], predicting future risk to humans and wildlife $[2,3]$, and determining appropriate management options [4]. Prior to our study, collection of

\footnotetext{
*Correspondence: emily.chenery@mail.utoronto.ca

${ }^{1}$ Department of Physical and Environmental Sciences, University

of Toronto Scarborough, 1265 Military Trail, Scarborough, Ontario M1C

1A4, Canada

Full list of author information is available at the end of the article
}

the off-host, larval life stage of the winter tick, Dermacentor albipictus (Packard, 1869) had not been documented at what is believed to be one of the northernmost limits of their range, in Yukon Territory, Canada [5-7].

Dermacentor albipictus is a one-host ixodid tick with a one-year life-cycle, which primarily feeds on cervids such as moose (Alces alces), elk (Cervus canadensis), caribou (Rangifer tarandus), and deer (Odocoileus sp.). Although it shows no host specificity, infestation in moose is wellknown for causing significant hair and blood loss, the effects of which can be fatal $[6,8,9]$. Winter ticks have also been implicated in the death of elk, showing similar 
pathological features [10]. It is not known to be a vector of any significant diseases of public or wildlife health concern, although ongoing research suggests $D$. albipictus may be a reservoir for some pathogens, such as pseudorabies [11] and Babesia duncani [12].

The initial introduction of $D$. albipictus to Yukon was likely through the translocation of elk from Elk Island National Park, Alberta, Canada, in the 1950s and 1990s [13-15]. Prior to this, the ticks were not believed to be present north of $60^{\circ} \mathrm{N}$ latitude $[5,6]$ though likely present up to $64^{\circ} \mathrm{N}$ latitude in the adjacent Northwest Territories $[5,13,16]$. Samuel's comprehensive survey of trappers in northwestern Canada in 1987 indicated that, anecdotally, some Yukon moose may have had hair loss indicative of D. albipictus infestation as far back as the 1930s [13], but no field studies had been otherwise conducted. Monitoring by the Yukon government has recorded nymphal and adult $D$. albipictus by examining cervid hides since 2012, but no larval ticks had been detected in the environment, despite multiple flagging attempts 2010-2012 [7, 15].

Here, we report for the first time the collection of larval D. albipictus, by flagging in 2018 and 2019, in important cervid habitat in Yukon, Canada, thus confirming that winter ticks are successfully completing their life-cycles despite the high latitude.

\section{Methods}

The Ibex Valley is located in the Boreal Cordillera ecoregion of southern Yukon, Canada $\left(60^{\circ} 50^{\prime} 42^{\prime \prime} \mathrm{N}\right.$, $135^{\circ} 38^{\prime} 18^{\prime \prime} \mathrm{W}$, elevation $c .721 \mathrm{~m}$ ), approximately $16 \mathrm{~km}$ west of the city of Whitehorse (Fig. 1). It is primarily settlement land of the Champagne and Aishihik and Kwanlin Dün First Nations and is presently undeveloped, with a few agricultural holdings of livestock and private residences. The approximately $152 \mathrm{~km}^{2}$ area also forms the core range for a managed population of elk (Cervus canadensis) that moved into this region following their introduction in 1959 [15, 17]. Other potential host species found here include moose, mule deer (Odocoileus hemionus), and semi-feral horses (Equus caballus). Vegetation composition is mixed, with characteristic boreal forests of conifers mixed with wetlands and aspen stands, interspersed with dry, grassy southfacing slopes and glacial lacustrine valley bottoms [18]. Several areas have shown slow regeneration since forest fires in 1958 [18] and are sparsely vegetated.

The Ibex Valley formed part of a pilot study in 2018 aimed at obtaining an initial detection of D. albipictus larval presence, and it was the only location where any larvae were found (Fig. 1). In 2019, all sampling efforts focused on this region with the aim of confirming larval detections made the previous year. Twelve sites, each a minimum of $500 \mathrm{~m}^{2}$ were selected across the valley based on habitat type (sub-polar grassland, barrenground) and host activity (game trails, pellets, tracks). One additional site was also chosen in the Braeburn elk range $\left(61^{\circ} 25^{\prime} 20.2^{\prime \prime} \mathrm{N}, 135^{\circ} 43^{\prime} 52.1^{\prime \prime} \mathrm{W}\right.$, elevation $\left.c .835 \mathrm{~m}\right)$, $40 \mathrm{~km}$ to the north of Ibex Valley. Flagging was conducted at each site, focussing on areas with visible cervid game trails. Sampling events were repeated, at minimum, every two weeks from 26 August to 30 November 2019 during daylight hours and did not take place on days of heavy rain or high winds but continued after snowfall (8 October 2019 onwards). Low densities of larval ticks were immediately removed from flag samplers in the field using lint rollers, and lint sheets were placed in sealed plastic bags. Flags with high larval abundances were removed and placed directly in sealed bags. All lint and flag samples were labelled in the field and returned to the lab for identification and counting. Where possible, questing vegetation was identified to family or species level in the field, consistent with Cody (2000) [19]. Vouchers and photographs were collected of any species not positively identified in the field and were later identified with the assistance of a Yukon Government expert (B. Bennett, pers. comm., 26/09/19). Local temperature and relative humidity data were collected for each sampling location using a Kestrel environmental meter (Kestrel 5000 handheld Environmental Meter, NielsenKellerman PA, USA). In both sampling years, tick identification was carried out via microscopy on a subset of each sample, based on morphological characteristics provided in Lindquist et al. and as reported in Clifford et al. [20, 21]. Additionally, in 2018, several specimens were preserved in $70 \%$ ethanol and submitted for confirmatory identification (Canadian Science Centre for Human and Animal Health, Winnipeg, Manitoba, Canada). All larvae were confirmed to be D. albipictus and no other tick species were detected.

\section{Results and discussion}

A cumulative total of $6,924 \mathrm{D}$. albipictus larvae were collected across Ibex Valley in 2018 (21 September-18 October), and 135,582 in 2019 (30 August-30 November). Approximate densities ranged from 0.22-146.2 larvae per $100 \mathrm{~m}^{2}$ in 2018, and from 0.044 larvae per 100 $\mathrm{m}^{2}$ in 2019 (Figs. 1, 2). The difference, in both detection periods and approximate numbers and densities of ticks per season, is likely due to our increased knowledge of suitable sampling locations and associated efforts in 2019 , rather than a reflection of actual tick activity each year. A total of 7238 D. albipictus larvae, ranging 184.83293.7 larvae per $100 \mathrm{~m}^{2}$, were also collected in Braeburn in 2019 during two sampling events (19 September and 4 October). Only sites in Ibex Valley were sampled until 30 


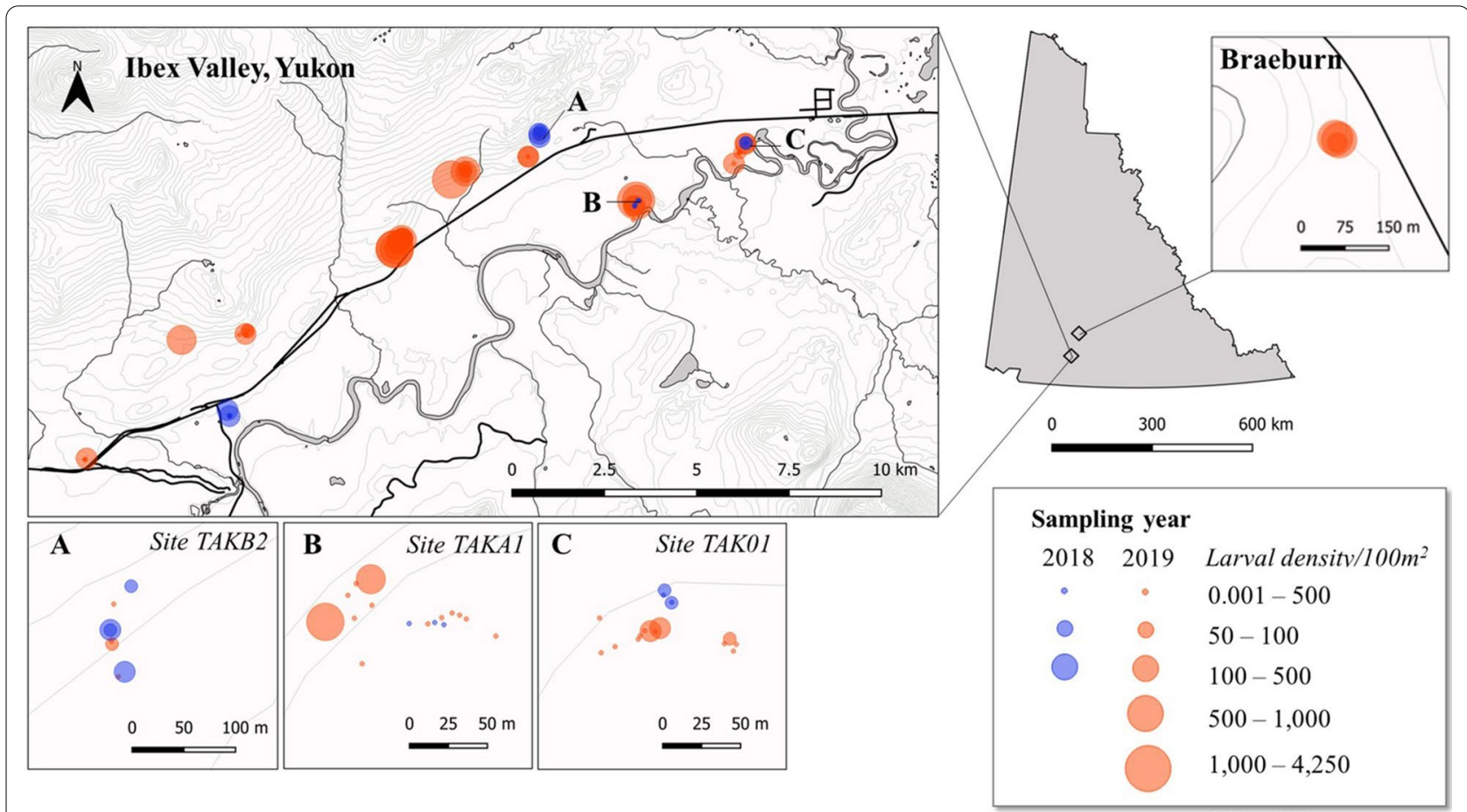

Fig. 1 Locations of larval tick sampling sites in 2018 (blue) and 2019 (orange) in Ibex Valley and Braeburn, Yukon, Canada, either side of the Alaska Highway (black line). Bubble size indicates the average densities of D. albipictus larvae collected per $100 \mathrm{~m}^{2}$. Highest larval densities sampled were in the central region of Ibex Valley, and at Braeburn. Larvae were often detected at almost identical locations in 2019 as the previous year (inset: $\mathbf{a}$, b) or at very close proximity to these locations (inset: c)

November 2019, but it seems plausible that larvae continue actively questing at all previous tick detection locations until at least this date. In all but one of the locations where larvae were found in 2018, larvae were also present in 2019, often at almost identical points (Fig. 1: insets A, $\mathrm{B}$ ), or in extremely close proximity to the previous sampling points (Fig. 1: inset $C$ ). This finding suggests a high degree of site fidelity among cervid and equine hosts may result in spatial 'hotspots' of larvae that are consistent year-to-year.

We observed larvae actively questing from 30 August to 29 November 2019. On average, the number of larvae collected per day across all tick-positive sampling sites was highest during the last week of September and first week of October (Fig. 2). Due to the limited data available for 2018, conclusions regarding questing peak for that year cannot be drawn. This apparent peak in questing activity observed in 2019 is similar to the reported behaviour for $D$. albipictus elsewhere in North America [22-26], and a lack of difference in the north may indicate that questing is not solely driven by temperature, as has been previously suggested [5, 24-26]. Temperature and relative humidity measured on site over this sampling period varied considerably, from -2.3 to $33.5^{\circ} \mathrm{C}$, and $15.1-91.5 \%$, respectively (Table 1 ).
Field temperatures were generally warmer than the daily reported averages by $5-19{ }^{\circ} \mathrm{C}$, reinforcing the value of field measures in capturing microhabitat conditions influential for tick survival and development at this high latitude (Table 1). Critically, previous laboratory experiments of the cold tolerance of $D$. albipictus from New Hampshire, USA, have suggested unlikely survival of larvae after contact with ice [27], yet we frequently observed active larvae under these conditions in the field in Yukon (Fig. 3). Previous genetic analysis of a sample of Yukon D. albipictus adults suggested that this population is most likely a combination of translocated ticks from Elk Island National Park in Alberta, Canada, and $D$. albipictus that have expanded their range from nearby northern British Columbia [14]. Early experiments have also shown that adult females are capable of egg-laying in adjacent Alaska [28], suggesting that environment and habitat may not be as critical a limiting factor in this species' distribution, as once thought $[5,6,15]$. In absence of any clear genetic differences, however, we might hypothesise that phenotypic changes may have arisen in this Yukon population in the decades since their first arrival. Given this, and the apparent discrepancy between our observations and those of $D$. albipictus survival in more southerly 
regions (e.g. [27]), further comparisons between northern and southern populations of $D$. albipictus larvae may be warranted to determine if there are significant differences in their ability to tolerate environmental extremes across latitudes.

Most questing aggregations were observed on grasses, particularly Calamagrostis purpurea, however, larvae were also found on other vegetation where it was available (Fig. 4a). No detections were made in coniferous forest or closed canopy areas, consistent with previous studies of egg development and hatching success [23, 29]. Questing aggregations ranged vertically from $13-82$ $\mathrm{cm}$ above ground level, with an average questing height of $56.8 \mathrm{~cm}$ (Fig. 4b), or generally the observed maximum height of available vegetation. Experimental studies have shown $D$. albipictus will preferentially aggregate at twice the maximum we observed, around $120 \mathrm{~cm}$, or cervid host torso height [22]. Given ongoing infestation of Yukon cervids, vegetation height alone does not appear to be significantly limiting larval transmission to hosts in this system.

Understanding the location of the larval stage of $D$. albipictus may have important implications for future management of this species. Strategic burning of
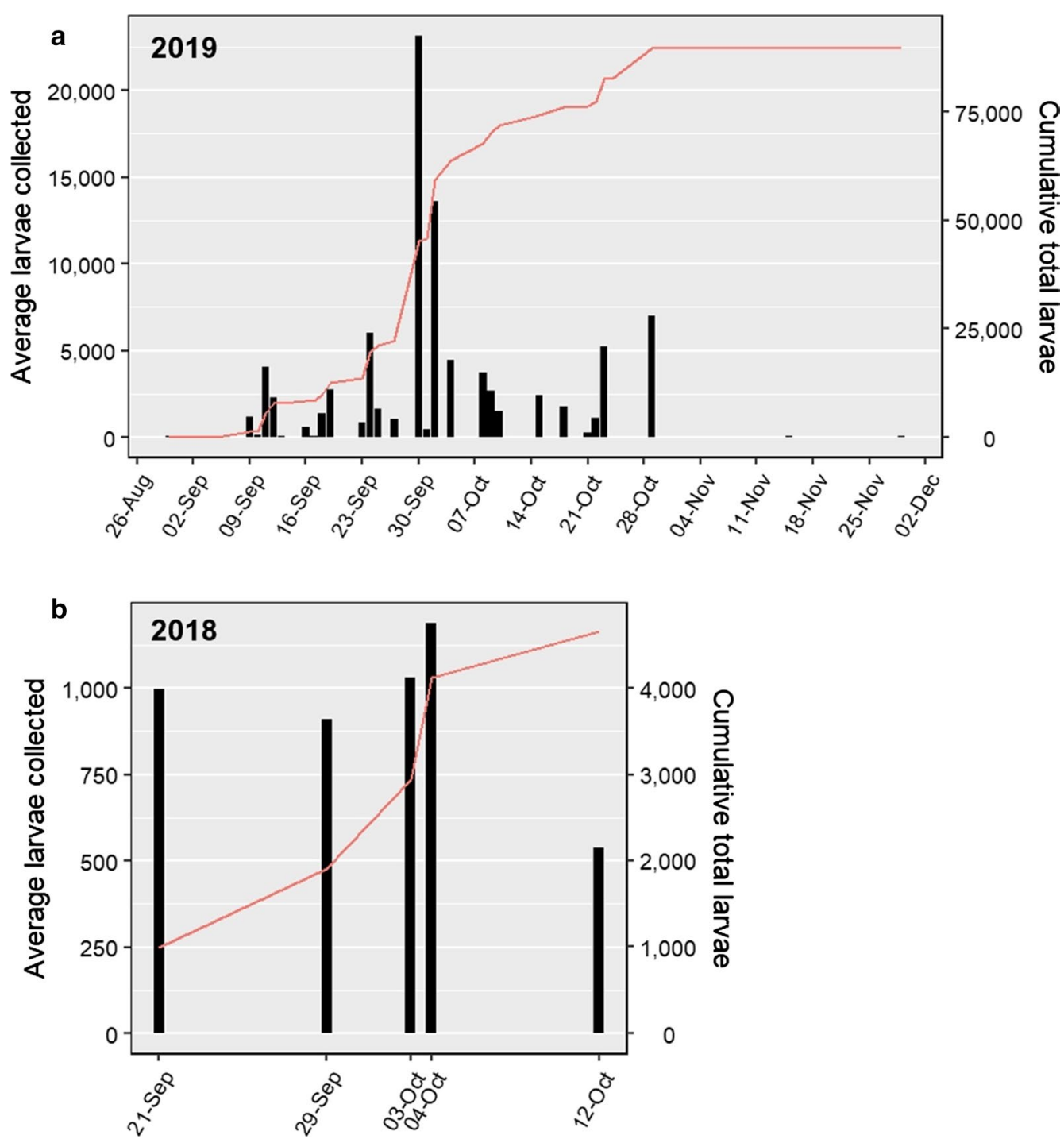

Fig. 2 Average number of D. albipictus larvae collected per sampling day (black bars) and cumulative total (red line) across all sites sampled in Ibex Valley, 2019 (a) and 2018 field seasons (b). Although two weeks of sampling were missed end of October-beginning of November 2019, both average daily collection numbers and cumulative total suggest that peak questing most likely occurred during the last week of September and first week of October 
Table 1 Averaged weekly measurements of temperature and relative humidity, collected in the field across sampling locations in 2019, Ibex Valley, Yukon, Canada

\begin{tabular}{|c|c|c|c|c|c|c|c|c|}
\hline \multicolumn{2}{|c|}{ Sampling week, 2019} & \multicolumn{3}{|c|}{ Temperature $\left({ }^{\circ} \mathrm{C}\right)$} & \multirow[t]{2}{*}{ 5-day mean } & \multicolumn{3}{|c|}{ Relative humidity (\%) } \\
\hline & & \multirow{2}{*}{$\begin{array}{l}\operatorname{Min} \\
-\end{array}$} & \multirow{2}{*}{$\frac{\text { Mean }}{-}$} & \multirow[t]{2}{*}{$\operatorname{Max}$} & & \multirow{2}{*}{$\begin{array}{l}\text { Min } \\
-\end{array}$} & \multirow{2}{*}{$\begin{array}{l}\text { Mean } \\
-\end{array}$} & \multirow{2}{*}{$\frac{\text { Max }}{-}$} \\
\hline 1 & 19-24 August & & & & 7.9 & & & \\
\hline 2 & 26-31 August & 25.0 & 27.8 & 33.5 & 8.8 & 23.9 & 25.1 & 25.7 \\
\hline 3 & 2-07 September & 23.0 & 23.4 & 25.0 & 18.2 & 29.5 & 35.7 & 44.8 \\
\hline 4 & 9-14 September & 16.7 & 21.2 & 29.7 & 8.8 & 15.6 & 34.8 & 59.6 \\
\hline 5 & 16-21 September & 13.7 & 17.3 & 20.1 & 10.2 & 39.9 & 51.1 & 69.2 \\
\hline 6 & 23-27 September & 12.0 & 16.1 & 22.6 & 5.4 & 25.5 & 33.2 & 59.0 \\
\hline 7 & 30 September-5 October & 8.0 & 15.0 & 19.5 & - & 34.6 & 54.6 & 91.5 \\
\hline 8 & 7-12 October & -2.3 & 5.8 & 9.7 & - & 46.4 & 56.1 & 67.7 \\
\hline 9 & 14-19 October & 0.9 & 1.8 & 3.6 & - & 33.0 & 50.4 & 85.3 \\
\hline 10 & 21-26 October & 3.6 & 4.8 & 5.6 & -2.6 & - & 52.0 & - \\
\hline 11 & 28 October-2 November & 6.1 & 6.2 & 6.3 & -0.5 & - & 56.2 & - \\
\hline 12 & 4-9 November & - & - & - & -7.7 & - & - & - \\
\hline 13 & 11-16 November & -0.6 & 2.5 & 6.0 & -7.7 & 69.6 & 70.5 & 71.3 \\
\hline 14 & 18-23 November & 4.6 & 5.2 & 5.8 & -0.4 & 50.1 & 55.6 & 61.1 \\
\hline 15 & 25-30 November & - & -0.5 & - & -10.7 & - & 58.3 & - \\
\hline
\end{tabular}

Notes: Five-day mean values for temperature were calculated from daily averages reported at the nearest meteorological station (Takhini River Ridge: $60^{\circ} 56^{\prime} 45.0^{\prime \prime} \mathrm{N}$, $135^{\circ} 34^{\prime} 23.0^{\prime \prime W}$, elevation $671 \mathrm{~m}$ ) [33]. Mean values for relative humidity were not available. Missing values are indicated by dashes and include weeks one and 12 when sampling was absent

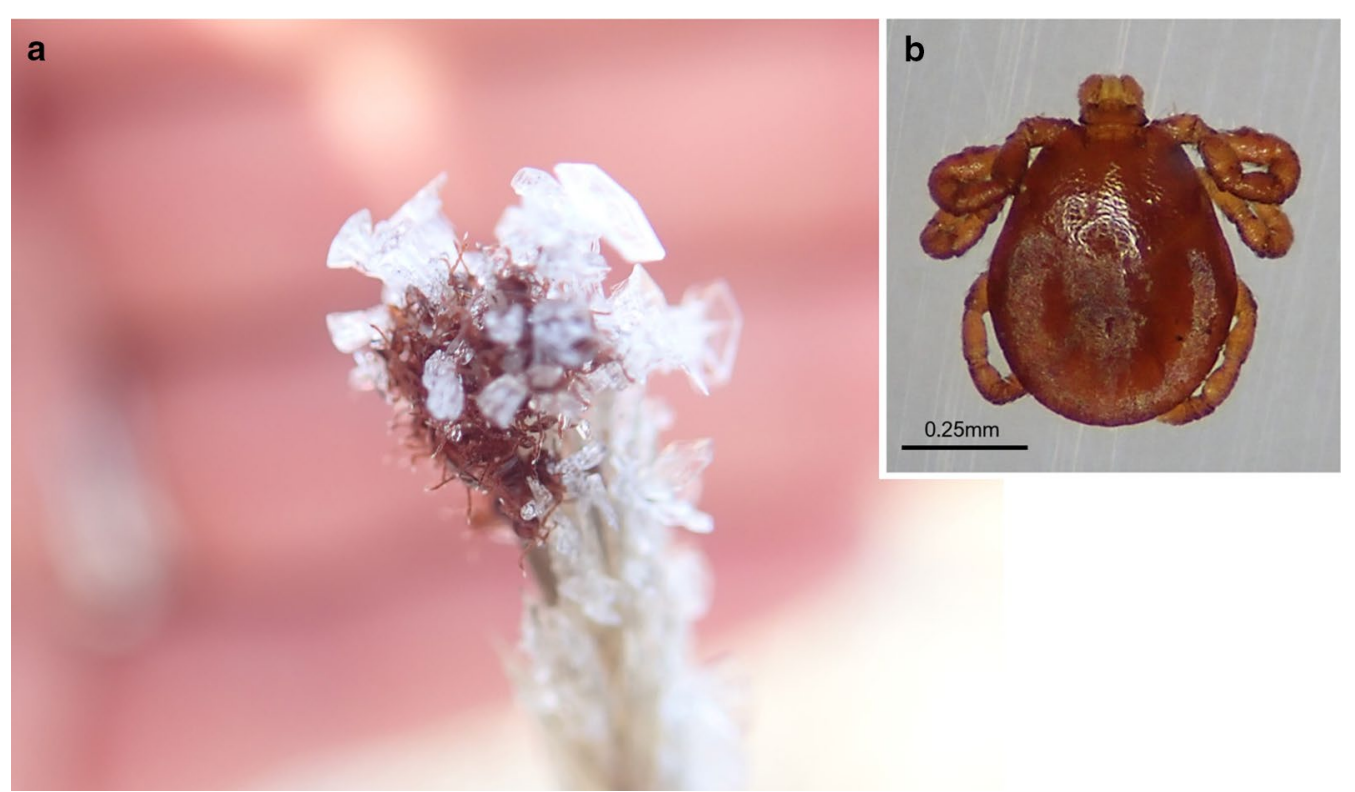

Fig. 3 a Larvae of D. albipictus actively questing beneath ice crystals, Ibex Valley, Yukon, Canada, on 21 October 2019. Once contact was made, these larvae were still capable of attaching to a flag sheet, suggesting that relatively extreme conditions in early winter may not significantly reduce transmission to a host during this period. b Magnified dorsal view of D. albipictus larva. (Image credits: E.S. Chenery)

known larval hotspots has been proposed as a shortterm control measure [30], or the development of known predators of larvae, such as entomopathogenic fungi, as a topically applied biological control agent [31]. Although there is little evidence that Yukon wildlife are currently adversely affected by tick infestation, the negative impact of $D$. albipictus hyperabundance elsewhere in North America suggests monitoring locations where larvae are found may provide options for proactive management or mitigation in future. 

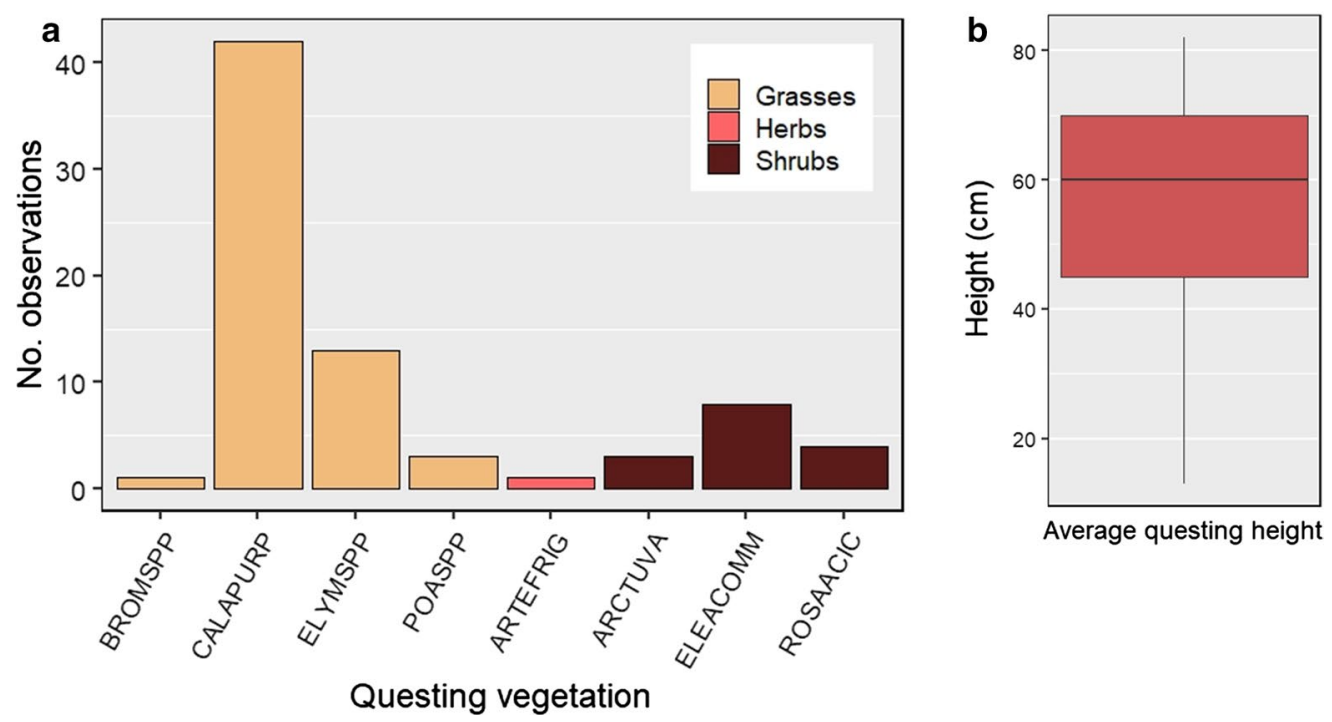

Fig. 4 a Vegetation species and groups upon which larval D. albipictus were found questing in 2018 and 2019. Species codes are as follows: (Grasses) BROMSPP = Bromus sp., CALAPURP = Calamagrostis purpurea; ELYMSPP = Elymus sp., POASPP $=$ Poa sp.; (Herbs) ARTEFRIG = Artemisia frigida; (Shrubs) ARCTUVA = Arctostaphylos uva-ursi, ELEACOMM = Eleagnus commutata, ROSAACIC = Rosa acicularis. b Average height of questing aggregations, 2018 and 2019. In almost all cases, questing height was identical to the observed maximum height of the vegetation available

Our confirmed detection of D. albipictus larvae in Yukon using the flagging method represents a significant step in accumulating knowledge of this species in-situ in northern regions. All previous reported detections in Yukon and neighbouring Northwest Territories have been of adult and nymphal D. albipictus, either on-host $[15,16]$, or through anecdotal reports of potentially related hair loss on moose [13]. Detection of the off-host life stages of this tick provides evidence that suitable conditions exist for D. albipictus to complete its whole life cycle in Yukon, corroborating previous assertions of establishment potential [13, 28, 32], and provides critical information to inform ongoing monitoring and potential management or mitigation. Our detection may also forewarn of other tick species able to expand their range in the north, in line with a warming climate.

\section{Acknowledgements}

We wish to thank Champagne and Aishihik First Nations and Kwanlin-Dün First Nation for permission to sample on their lands, field assistants D. Gordon, C. Bradley and M. Henaff, and the many undergraduate students at the University of Toronto Scarborough who assisted in conducting larval counts. Field research was carried out under Yukon-Canada Scientist and Explorers Licence (licence number 19-19S\&E) issued by the Department of Tourism and Culture, Government of Yukon, Canada, and Wildlife Research Permit (permit number WRP-0304) issued by Department of Environment, Government of Yukon, Canada.

\section{Authors' contributions}

ESC, NJH and PKM conceived the study and obtained funding to support the research. ESC, PKM, and NEM designed the flagging study methodology. ESC conducted the investigation in the field, collected and analysed all larval and environmental data, visualised the data and wrote the original manuscript. PKM and NEM provided supervisory support to ESC, and NJH provided access to resources and laboratory space for tick sample processing. All authors read and approved the final manuscript.

\section{Funding}

This research was supported by the Climate Change Preparedness in the North Program of Crown-Indigenous Rural and Northern Affairs Canada (CCPN-CIRNAC) (PKM, NJH), a Natural Sciences and Engineering Research Council of Canada (NSERC) Discovery Grant (PKM, NEM), the Canada Foundation for Innovation (CFI) John R. Evans Leaders Fund (PKM), the Ministry of Research, Innovation and Sciences (MRIS) Ontario Research Fund (PKM), and a W. Garfield Weston Foundation Fellowship, through the Wildlife Conservation Society Canada (ESC).

\section{Availability of data and materials}

The datasets used and/or analysed during the current study are available from the corresponding author on request.

\section{Ethics approval and consent to participate}

Not applicable.

\section{Consent for publication}

Not applicable.

\section{Competing interests}

The authors declare that they have no competing interests.

\section{Author details}

1 Department of Physical and Environmental Sciences, University of Toronto Scarborough, 1265 Military Trail, Scarborough, Ontario M1C 1A4, Canada.

${ }^{2}$ Animal Health Unit, Environment Yukon, 10 Burns Road, Whitehorse, Yukon Y1A 4Y9, Canada. ${ }^{3}$ Department of Biological Sciences, University of Toronto Scarborough, 1265 Military Trail, Scarborough, Ontario M1C 1A4, Canada.

Received: 26 May 2020 Accepted: 24 October 2020

Published online: 11 November 2020 


\section{References}

1. Clow KM, Ogden NH, Lindsay LR, Russell CB, Michel P, Pearl DL, Jardine CM. A field-based indicator for determining the likelihood of Ixodes scapularis establishment at sites in Ontario. Canada PLOS ONE. 2018;13:e0193524.

2. Zeman P, Benes C. Spatial distribution of a population at risk: An important factor for understanding the recent rise in tick-borne diseases (Lyme borreliosis and tick-borne encephalitis in the (zech Republic). Ticks Tick Borne Dis. 2013:4:522-30.

3. Arsnoe I, Tsao Jl, Hickling GJ. Nymphal Ixodes scapularis questing behavior explains geographic variation in Lyme borreliosis risk in the eastern United States'. Ticks Tick Borne Dis. 2019;10:553-63.

4. Stafford KC III, Kitron U. Environmental management for Lyme borreliosis control. In: Gray JS, Kahl S, Lane RS, Stanek G, editors. Lyme Borreliosis Biology, Epidemiology and Control. Wallingford: CABI Publishing; 2002. p. 301-34.

5. Wilkinson PR. The distribution of Dermacentor ticks in Canada in relation to bioclimatic zones. Can J Zool. 1967;45:517-37.

6. Samuel WM. White as a ghost: winter ticks and moose. Alberta: Federation of Alberta Naturalists; 2004

7. Environment Yukon. Summary of winter tick management operations 2008-2010. Government of Yukon, Whitehorse; 2010. (Unpublished report).

8. Seton ET. Lives of game animals. Volume 3 Part I: Hoofed animals. 3rd Edition, Boston, USA: Charles T. Branford Company; 1953.

9. Jones H, Pekins PJ, Kantar L, Sidor I, Ellingwood D, Lichtenwalner A, O'Neal M. Mortality assessment of calf moose (Alces alces) during successive years of winter tick (Dermacentor albipictus) epizootics in New Hampshire and Maine.' Can J Zool. 2018;97:22-30.

10. Calvente E, Chinnici N, Brown J, Banfield JE, Brooks JW, Yabsley MJ. Winter tick (Dermacentor albipictus)-associated dermatitis in a wild elk (Cervus canadensis) in Pennsylvania, USA. J Wildl Dis. 2020;56:247-50.

11. Musante AR, Pedersen $K$, Hall P. First reports of pseudorabies and winter ticks (Dermacentor albipictus) associated with an emerging feral swine (Sus scrofa) population in New Hampshire. JWildl Dis. 2014;50:121-4.

12. Swei A, Connor KE, Couper LI, Thekkiniath J, Conrad PA, Padgett KA, et al. Evidence for transmission of the zoonotic apicomplexan parasite Babesia duncani by the tick Dermacentor albipictus. Int J Parasitol. 2019:49:95-103.

13. Samuel WM. Locations of moose in northwestern Canada with hair loss probably caused by the winter tick, Dermacentor albipictus (Acari: Ixodidae). J Wildl Dis. 1989;25:436-9.

14. Leo SST, Samuel WM, Pybus MJ, Sperling FA. Origin of Dermacentor albipictus (Acari: Ixodidae) on elk in the Yukon. Canada J Wildl Dis. 2014;50:544-51.

15. Environment Yukon. Management plan for elk in Yukon. Government of Yukon. 2016. https://yukon.ca/en/management-plan-elk-yukon-2016. Accessed 12 Dec 2019.

16. Kashivakura CK. Detecting Dermacentor albipictus, the winter tick, at the northern extent of its distribution range: Hunter-based monitoring and serological assay development. MSc Thesis, University of Calgary, Alberta, Canada; 2013

17. Strong WL, Chambers JHS, Jung TS. Range constraints for introduced elk in southwest Yukon. Canada Arctic. 2013:66:470-82.
18. Smith CAS, Meikle JC, Roots CF. Ecoregions of the Yukon Territory: Biophysical properties of Yukon landscapes. Agriculture and Agri-Food Canada, PARC Technical Bulletin No. 04-01, Summerland, British Columbia; 2004. https://data.geology.gov.yk.ca/Reference/67942.

19. Cody WJ. Flora of the Yukon Territory. Ottawa: National Research Press; 1996.

20. Lindquist EE, Galloway TD, Artsob H, Lindsay LR, Drebot M, Wood H, Robbins RG. A handbook to the ticks of Canada (Ixodida: Ixodidae, Argasidae). Biological Survey of Canada Monograph Series 7: 2016.

21. Clifford CM, Anastos G, Elbl A. The larval ixodid ticks of the eastern United States. Misc Pub Entomol Soc Am. 1961;2:213-37.

22. McPherson M, Shostak AW, Samuel WM. Climbing simulated vegetation to heights of ungulate hosts by larvae of Dermacentor albipictus (Acari: Ixodidae). J Med Entomol. 2000;37:114-20.

23. Addison EM, McLaughlin RF, Addison PA, Smith JD. Recruitment of winter ticks (Dermacentor albipictus) in contrasting forest habitats, Ontario. Canada Alces. 2016;52:29-40.

24. Drew ML, Samuel WM. Factors affecting transmission of larval winter ticks, Dermacentor albipictus (Packard), to moose, Alces alces, in Alberta. Can J Wildl Dis. 1985:21:274-82.

25. Aalangdong, OI. Winter tick ecology and transmission in Elk Island National Park, Alberta. MSc Thesis, University of Alberta, Edmonton, Alberta, Canada; 1994.

26. Samuel WM, Welch DA. Winter ticks on moose and other ungulates: factors influencing their population size'. Alces. 1991;27:169-82.

27. Holmes CJ, Dobrotka CJ, Farrow DW, Rosendale AJ, Benoit JB, Pekins PJ, Yoder JA. Low and high thermal tolerance characteristics for unfed larvae of the winter tick Dermacentor albipictus (Acari: Ixodidae) with special reference to moose. Ticks Tick Borne Dis. 2018:9:25-30.

28. Zarnke RL, Samuel WM, Franzmann AW, Barrett R. Factors influencing the potential establishment of the winter tick (Dermacentor albipictus) in Alaska. J Wildl Dis. 1990;26:412-5.

29. Drew ML, Samuel WM. Reproduction of the winter tick, Dermacentor albipictus, under field conditions in Alberta. Can J Zool. 1986;64:714-21.

30. Drew ML, Samuel WM, Lukiwski GM, Willman JN. An evaluation of burning for control of winter ticks, Dermacentor albipictus, in central Alberta. J Wild Dis. 1985;21:313-5.

31. Yoder JA, Pekins PJ, Nelson BW, Randazzo CR, Siemon BP. Susceptibility of winter tick larvae and eggs to entomopathogenic fungi - Beauveria bassiana, Beauveria caledonica, Metarhizium anisopliae, and Scopulariopsis brevicaulis. Alces. 2017;53:41-51.

32. Kutz SJ, Jenkins EJ, Veitch AM, Ducrocq J, Polley L, Elkin B, Lair S. The Arctic as a model for anticipating, preventing, and mitigating climate change impacts on host-parasite interactions. Vet Parasitol. 2009;163:217-28.

33. Historical Climate Data. Environment and Climate Change Canada (ECCC). 2019. https://climate.weather.gc.ca. Accessed 1 May 2020.

\section{Publisher's Note}

Springer Nature remains neutral with regard to jurisdictional claims in published maps and institutional affiliations. 